\title{
Historia(s) de la diferencia: la novela inglesa de mujeres en el siglo XIX
}

\author{
Ana Moya \\ Universidad de Barcelona

\section{(Hi)stories of Difference: Women's Novels in England in the Nineteenth Century}

\section{RESUMEN}

La novela británica, desde la Revolución

Francesa a la Primera Guerra Mundial, difícilmente puede apreciarse globalmente si se descarta el papel que juega la mujer,

no solamente como lectora sino también como escritora, dentro del panorama

literario y de desarrollo del pensamiento en el mundo anglosajón. Este trabajo propone una lectura crítica de la novela escrita por mujeres a lo largo del siglo $X I X$, con el fin de releer la representación de la diferencia, es decir, del Otro femenino en la cultura anglosajona, así como sus ramificaciones críticas y culturales. Tomando como punto de partida el planteamiento crítico de Judith Halberstam sobre la mujer masculina (female masculine), el trabajo propone una revisión crítica de la novela escrita por

mujeres en Inglaterra a lo largo del siglo $X I X$, entendiendo éste ideológicamente, el comprendido entre la Revolución Francesa y la Primera Guerra Mundial. La tesis fundamental que se explora en esta aportación se centra alrededor de la manera en que, por una parte, la mujer novelista supone una subversión del modelo de feminidad impuesto culturalmente a lo largo del siglo XIX.

Asimismo, y por otra parte, se analizará cómo las novelas que estas mujeres escriben se convierten en un foro de debate sobre la mujer, su naturaleza y su papel en la sociedad inglesa del momento.

Finalmente, el trabajo demostrará que la

\section{SUMMARY}

The English novel, from the French Revolution to WWI, can hardly be understood in its complexity without taking into consideration the role of women not only as writer but also as reader, within the literary and cultural panorama of the period. This article offers a critical reading of the novel written by women in the nineteenth century in England in order to re-read the representation of difference (the female Other in English culture) and explore its critical and cultural ramifications. The paper will take Judith Halberstam's notion of female masculinity as a starting point to reviewing the novel written by women in England in the nineteenth century in its wide sense, that is, from the French Revolution to WWI. The paper will suggest that the female novelist is in itself a subversion of the conventional notion of femininity dominant throughout the nineteenth century. At the same time, the paper will discuss the extent to which the novels written by these women writers become in themselves sites of debate about the role and nature of women in society at that time. Finally, the paper will state that revising the contribution of the woman novelist to culture, in this period and context, is critically and historically relevant even today to understand the construction and representation of the female Other, the (hi)stories of difference. 
revisión de la contribución cultural de la mujer novelista, dentro de este período y contexto concretos, es crítica e históricamente relevante aún hoy en día para comprender las construcciones y representaciones culturales del Otro femenino, las historias de la diferencia.

PALABRAS CLAVE: Historia Cultural, Estudios de la mujer, Narrativa inglesa, Literatura del siglo XIX, Judith Halberstam
KEY WORDS:

Cultural History, Women's Studies, English Fiction, Nineteenth Century Literature, Judith Halberstam

\title{
1. INTERTEXTUALIDAD, DIALOGISMO, HISTORIA Y LITERATURA
}

\author{
¿Hemos conocido alguna vez «lo real», excepto a través de sus representa- \\ ciones? ${ }^{1}$
}

Según Roland Barthes, las narrativas del mundo son innumerables ${ }^{2}$. Para Barthes la narrativa es, ante todo, una prodigiosa variedad de géneros que a su vez se puede plasmar a través de diferentes medios. Barthes define la narrativa como susceptible de ser expresada en el lenguaje articulado (tanto oral como escrito), en imágenes o gestos, por ejemplo. Argumenta, asimismo, que la narrativa está presente en los mitos, leyendas, fábulas, novelas, biografías, en la historia, la pintura, el cine e, incluso, en la conversación. Por otra parte, la narrativa está presente en todas las épocas de la historia en una forma u otra, en todos los lugares y sociedades, de manera que podemos concluir que empieza con la historia de la humanidad y permanece desde entonces. De hecho, los estudios más recientes de narratología ${ }^{3}$ argumentan que la narrativa es inseparable de la representación de la identidad, ya que es tan inherente al ser humano como el lenguaje. Bennet y Royle, en esta misma dirección, ofrecen cinco proposiciones alrededor de las cuales es posible orientar una discusión sobre la narrativa4: (1) las historias están

1 HUTCHEON, Linda, The Politics of Postmodernism. Londres, Routledge, 1989, p. 31 [Traducción propia].

2 BARTHES, Roland, «Introduction to the Structural Analysis of Narrative» en SONTAG, Susane (ed.), A Roland Barthes Reader. Londres, Vintage, 1994, pp. 251-252.

3 Entendiendo por narratología la teoría y estudio sistemático de la narrativa. En el entorno anglosajón que nos ocupa, podemos referir a modo de ejemplo los trabajos de BAL, Mieke, Narratology. Introduction to the Theory of Narrative. Toronto, University of Toronto Press, 1997 [1985]; CURRIE, Mark, Postmodern Narrative Theory. Londres, Macmillan, 1998; MCQUILLAN, Martin (ed.), The Narrative Reader. Londres y Nueva York, Routledge, 2000; y HUGHES, George, Reading Novels. Nashville, Vanderbilt University Press, 2002.

4 BENNET, Andrew y N. ROYLE, Nicholas, An Introduction to Literature, Criticism and Theory: Key Critical Concepts. Londres, Prentice Hall, 1995, p. 41. 
en todas partes; (2) no solamente contamos historias, sino que las historias nos cuentan también a nosotros; (3) el acto de contar una historia está inevitablemente ligado al ejercicio del poder, la propiedad y el dominio; (4) las historias son múltiples, de forma que siempre hay más de una y (5) las historias siempre cuentan algo sobre sí mismas, de forma que tienen inevitablemente dimensiones autoreflexivas. De hecho, la narratología del siglo XXI parte generalmente de la premisa conforme a la cual la narrativa está en todas partes, puesto que es el modo de pensar y existir del ser humano y, por lo tanto, considera que cualquier aproximación adecuada a su estudio pasa por ser necesariamente interdisciplinar.

Asimismo, los críticos literarios y textuales hoy en día aceptan generalmente que cualquier texto carece de significado independiente ${ }^{5}$. Es decir, el significado de un texto se encuentra no tanto en el texto en sí, sino más bien en las relaciones que se pueden establecer entre ese texto y todos aquellos a los que se refiere o con los que se puede relacionar, de manera que depende de una red de relaciones textuales. La intertextualidad de todo texto apunta a su naturaleza inevitablemente plural, reversible y abierta a las presuposiciones del propio lector. Los textos, finalmente, carecen de límites claros y de una manera u otra se encuentran envueltos en la expresión o represión de las diferentes voces dialógicas que existen en la sociedad en un momento dado.

La novela, y en el caso que nos ocupa concretamente la novela británica decimonónica, es una forma de narrativa que tiene como dos de sus ingredientes esenciales la ficcionalidad y la construcción de un narrador que cuenta la historia que se narra. El primero de estos dos elementos, la ficcionalidad, se basa en el supuesto de que los personajes y sucesos que se narran en una novela, aunque puedan pretender realismo o incluso estén inspirados directamente en hechos o momentos reales, son ciertamente ficticios. Se trata de una diferencia a priori evidente entre una novela y un relato histórico. Sin embargo, y pese a su naturaleza como relato de ficción, la novela puede ser, y de hecho en el caso que nos ocupa a menudo lo es, de carácter realista. Esto quiere decir que si bien el relato puede basarse en la creación de unos personajes ficticios, el mundo que se recrea en la ficción muchas veces es en conjunto real y se mueve en unas coordenadas que se aplican en la realidad, siendo fidedigno respecto de la misma. La novela puede, incluso, tener precisamente ese objetivo: el de recrear un mundo real. Las novelas de Charles Dickens, por citar un caso, describen explícitamente la Inglaterra de la época, explorando dicha realidad con minuciosidad para crear un retrato realista de la época de claro valor histórico-cultural. Por otra parte, y como toda historia que se cuenta, la novela necesita un narrador, alguien que la cuente. Este narrador puede adoptar formas diferentes que van desde la narración anónima en tercera persona

5 Cabe referir aquí a la obra de Julia Kristeva (concepto de intertextualidad) y de Mijaíl Bajtin (concepto de dialogismo) como pensadores que han marcado un antes y un después en la consideracion crítica de la narrativa y del texto literario en general. 
hasta la narración en primera persona y en boca de uno de los personajes de la propia novela. La novela comparte con el relato histórico la construcción de un narrador en una determinada posición respecto al relato que se narra y que, como dicen Bennet y Royle, realiza al contar la historia un ejercicio no exento de poder, propiedad y dominio.

Para un lector del siglo XXI, la novela decimonónica constituye un documento de naturaleza ficcional pero a la vez de valor histórico que, sin duda, le ofrece la posibilidad de tener a su alcance una multiplicidad de visiones y lecturas de la época. Incluso centrándonos exclusivamente en los escritores considerados habitualmente canónicos, se puede argumentar sin temor a equivocarse el valor de su obra en el presente no sólo como texto literario sino también como documento histórico. Las novelas de autores como Jane Austen, las hermanas Brontë, Charles Dickens, W. M. Thackeray, George Eliot, Elizabeth Gaskell, Thomas Hardy, Rudyard Kipling o Joseph Conrad son para el lector actual fuentes de conocimiento de la realidad de la Inglaterra del siglo XIX con sus retratos de la situación de la mujer, la familia, el Imperio Británico, la clase media o la educación, por mencionar algunos, a lo largo del siglo.

Ahora bien, en el caso de la novela británica, y en este largo siglo que podemos decir que abarca desde la Revolución Francesa a la Primera Guerra Mundial, difícilmente puede apreciarse su envergadura si se descarta el papel que juega la mujer, no solamente como lectora sino también como escritora, dentro del panorama literario y de desarrollo del pensamiento en el mundo anglosajón. Este período, acotado en términos literarios por el Romanticismo y el Modernismo, comprende todo el siglo XIX en la cultura anglosajona, incluyendo en su centro la literatura victoriana. Dentro de este largo siglo XIX, el papel de mujeres escritoras de la talla de Jane Austen, las hermanas Brontë, Elizabeth Gaskell, George Eliot y Virginia Woolf es a día de hoy indiscutible, no solamente por su aportación a la novela inglesa en el sentido más amplio, sino por su papel relevante como feministas en tanto en cuanto «historiadoras de la mujer», es decir, escritoras conscientes de su naturaleza femenina y que se ocupan de explorar el universo femenino en su producción literaria, ofreciendo al lector una representación de la diferencia que pone de relieve la construcción cultural de la mujer en la cultura anglosajona a lo largo del siglo XIX. La aportación de la mujer a la narrativa inglesa y al desarrollo del pensamiento durante este período, sin embargo, tiene una envergadura a menudo más desconocida y olvidada pero que resulta relevante para comprender la construcción cultural del Otro femenino, así como su representación (la representación de la diferencia) en toda su complejidad. 


\section{LA MUJER EN LA INGLATERRA DEL SIGLO XIX}

Lo máximo que pueden hacer es enseñar a sus hijas los trucos para sobrevivir en el patriarcado agradando y uniéndose a hombres poderosos y económicamente viables ${ }^{6}$

La historia de la mujer en la Inglaterra del siglo XIX es un camino largo que se inicia de manera simbólica con la publicación de la obra seminal de Mary Wollstonecraft, Vindicación de los derechos de la mujer ( $A$ Vindication of the Rights of Woman) $(1792)^{7}$ y culmina cuando la mujer obtiene el derecho al voto en 1918, tras la Primera Guerra Mundial. Durante el siglo XVIII se creía que el centro de la vida femenina era el hogar y que la mujer podía realizarse únicamente como esposa y madre. Con el ascenso de la burguesía durante el siglo XIX, las clases pudientes (la ascendente y cada vez más poderosa clase media, juntamente con la aristocracia tradicional) reclaman poco a poco a la mujer que domine las artes del entretenimiento y ornamento para encantar al hombre en primera instancia y entretenerlo posteriormente. Esta tendencia tropieza, eso sí, con el horror que inspiraban las mujeres sabias. En cualquier caso, a lo largo del siglo XIX la mujer comienza a ser educada, no como un fin en sí mismo, sino como un medio para ampliar sus «gracias» de cara al sexo opuesto. La formación de la mujer es una especie de barniz en «cultura general» y así seguirá hasta bien entrado el siglo XX. Las mujeres de la época comienzan a aprender idiomas (francés principalmente), por ejemplo, si bien se les niega el acceso al conocimiento de las lenguas clásicas, en estos momentos consideradas la base de la educación del sexo masculino. En sintonía con la filosofía de vida puritana propia de la clase media del momento, se trata de que las mujeres acrediten «deseabilidad», por decirlo de alguna manera, más allá de su posición y fortuna para que sean elegibles como esposas adecuadas.

Aunque durante todo el siglo XIX la mujer sigue educándose principalmente en casa, es bien cierto que el interés creciente por la educación de las mujeres se refleja en la proliferación de internados para señoritas. En estos centros las mujeres son entrenadas en la supresión de todo impulso espontáneo. Aisladas completamente del mundo, las jóvenes son educadas con un único fin: la caza de marido. Una vez finalizada su preparación en las artes del entretenimiento y la ornamentación (música, pintura, idiomas modernos, costura y modales forman la esencia de la formación que se les da), estas jóvenes son arrojadas al mundo a conseguir el objetivo: un marido. La sociedad del momento margina a la mujer soltera, que es vista como un auténtico fracaso. En este entorno de clase media-alta, por supuesto está fuera de cuestión que la mujer aspire a una profesión, a la que única-

${ }^{6} \mathrm{RICH}$, Adrienne, On Lies, Secrets and Silences: Selected Prose 1966-1978. Nueva York, Norton, 1979, p. 91 [Traducción propia].

7 Wollstonecraft sostiene en esta obra que las mujeres no son por naturaleza inferiores al hombre, sino que se les niega el acceso a una educación adecuada. 
mente recurre en caso de necesidad. Desde Jane Austen, pasando por Thackeray o Dickens, por ejemplo, la novela en lengua inglesa de la época presenta multitud de ejemplos de esta situación, que casi siempre aparece como un aspecto de la vida de la mujer de carácter tragicómico.

El estatuto jurídico de las mujeres en la Inglaterra del siglo XIX separa enormemente a las solteras de las casadas, con claro perjuicio de estas últimas. Sucede así, y a pesar de que una mujer soltera y mayor de edad no tiene en ningún caso derecho a voto, no puede ejercer funciones oficiales ni practicar una profesión liberal, goza de los mismos derechos que el hombre en lo concerniente a los bienes muebles o inmuebles pudiendo disponer libremente de ellos en vida o por testamento. Por el contrario, la mujer casada se convierte desde el matrimonio en una esclava ante la ley en todo cuanto se refiere a sus bienes, sus hijos y a su misma persona. Hasta 1884 el marido tiene derecho sobre la persona misma de la mujer. Siguiendo la doctrina del Derecho Consuetudinario (Common Law), el matrimonio convierte al marido en propietario de todos los bienes de la mujer, a cambio de lo cual se obliga a protegerla y a satisfacer sus necesidades. El estatuto de la esposa en cuanto a los derechos sobre los hijos habidos en el matrimonio es también discriminatorio para la mujer. En 1837 la justicia no reconoce todavía a la esposa el derecho de abandonar a su marido salvo que él se reconociera culpable de crueldad sobre su persona, e incluso en el caso de que la ley no obligara a la esposa a reintegrarse al domicilio conyugal, el marido conserva todos los derechos sobre los bienes. La ley no concede la separación a la esposa por adulterio del marido. El padre tiene en estos momentos derechos ilimitados sobre sus hijos, pudiendo incluso separarlos completamente de su madre, quien no existe ante la ley, y confiarlos al cuidado de una persona de su elección. En 1939 se consigue la primera reforma con una nueva ley de custodia que contempla por primera vez que, en el caso de separación de los padres, la madre pueda presentar la petición de que la custodia de los hijos menores de siete años le sea concedida automáticamente así como que se regule el derecho de visita de los hijos mayores de esta edad. La ley de 1857 estipula que para abrir un proceso de divorcio basta con que el hombre pueda probar un acto de infidelidad de la esposa, mientras que ésta deberá probar el adulterio del marido, agravado por el abandono, crueldad, incesto, violación, sodomía o bestialidad. Será a partir de 1870 cuando se empiecen a registrar avances notables en lo que se refiere a la situación legal de la mujer casada y su derecho sobre los hijos.

Una vez casadas, las mujeres inglesas de esta época pasan gran parte de su tiempo en casa. La cada vez mayor afluencia de la clase media tiene como consecuencia la liberación de la mujer de las tareas domésticas, dejándola a menudo ociosa. El hogar se concibe como una unidad social, donde las funciones de hombre y mujer están perfectamente delimitadas, siendo entendidos ambos como los polos positivo y negativo de la misma realidad. El hombre burgués debe luchar por progresar en la sociedad, en el mundo exterior, mientras la función esencial de la mujer es preservar el hogar precisamente de la corrupción proveniente del mundo 
exterior. Para ello, la mujer debe mantenerse pura e incorrupta. Y así se impone en esta sociedad el ideal del «ángel de la casa» (the angel in the house), basado en el famoso poema que Coventry Patmore dedicó a su mujer Emily en 1854: Man must be pleased; but him to please is woman's pleasure («El hombre debe ser complacido; pero el placer de la mujer es complacerle»).

Como se ha visto, las décadas centrales del siglo XIX constituyen un período de consolidación y difusión del ideal burgués, un ideal de trabajo, austeridad, castidad y culto a la familia patriarcal y monogámica; ideales que contrastan con el modo de vida más relajado de una aristocracia progresivamente decadente y completamente ociosa. En los últimos años del siglo, sin embargo, se vislumbran fisuras importantes que apuntan a cambios necesarios que se producirán ya entrado el siglo XX. El puritanismo victoriano entra en decadencia y es abiertamente cuestionado desde una multitud de posiciones. La teoría de la evolución de Darwin, las emergentes ideologías socialistas, los movimientos sufragistas o los debates anti-colonialistas, son ejemplos claros de que algo está cambiando rápidamente. El ideal del «ángel de la casa» también comienza a ser cuestionado en este momento y aparece la «nueva mujer» (the new woman). Esta «nueva mujer» no es sino una reacción contra el culto a la domesticidad que el «ángel de la casa» había encapsulado. El movimiento es hacia la liberación de lo que se empieza a ver como un modelo altamente represivo y castrante para la mujer y la sociedad en general. En términos generales, este nuevo modelo de feminidad abandera una educación como la de los hombres para las mujeres; capacidad de ganar dinero y, por tanto, de ser financieramente independiente; participación en las discusiones políticas del país y poder de decisión sobre su vida tanto referida al matrimonio como a la maternidad, por ejemplo. Las cosas comienzan a cambiar. El símbolo más poderoso de que este cambio que ya no tiene retorno se produce, sin duda, cuando la mujer obtiene el derecho al voto en 1918.

8 Coventry Patmore (1823-1896), poeta y crítico inglés, ha pasado a la historia por su poema «The Angel in the House», que publicó en 1854 y, posteriormente, en una versión revisada en 1862. En un principio, el poema no recibió gran atención crítica, aunque su popularidad fue en aumento con el transcurrir de los años. Para Virginia Woolf, como es bien sabido, este ideal represivo era todavía demasiado potente entrado el siglo XX. En su ensayo «Professions for Women», resultado de una conferencia que dirigió al Women's Service League el 21 de enero de 1931 y cuyo texto fue después incluido en The Death of the Moth and Other Essays (1942), Woolf define al «ángel de la casa» en los siguientes términos: She was intensely sympathetic. She was immensely charming. She was utterly unselfish. She excelled in the difficult arts of family life. She sacrificed herself daily ... Above all -I need not say itshe was pure. Her purity was supposed to be her chief beauty - her blushes, her great day. In those days - the last of Queen Victoria - every house had its Angel (Era intensamente comprensiva. Inmensamente encantadora. Completamente desinteresada. Destacaba en las difíciles artes de la familia. Se sacrificaba diariamente ... Por encima de todo — no hace falta que lo diga- era pura. Su pureza se suponía su belleza fundamental — su rubor, su gran día. En aquellos días - los últimos de la reina Victoria- cada casa tenía su ángel) [Traducción propia].

http://s.spachman.tripod.com/Woolf/professions.htm. Fecha último acceso: 12 agosto 2010. 


\section{UNA NARRATIVA DE LA DIFERENCIA: LA MASCULINIDAD FEMENINA}

Parte de la ocupación de la mujer escritora es matar al "ángel de la casa»9

En «An Introduction to Female Masculinity: Masculinity without Men» ${ }^{10}$, una revisión de su libro Female Masculinity ${ }^{11}$, Judith Halberstam argumenta que la masculinidad es la expresión social y cultural de lo masculino (en tanto en cuanto referente al sexo masculino/varón) ${ }^{12}$. En este sentido, reivindica que lo que ella denomina «masculinidad femenina» no solamente no es una imitación de lo masculino (referente al varón), sino que se trata de un fenómeno que permite precisamente detectar la manera en que la masculinidad se construye como tal en la sociedad. Para Judith Halberstam, lo que conocemos como «masculinidad heroica» se ha producido por y a través de cuerpos tanto masculinos como femeninos. Halberstam argumenta en su ensayo que la masculinidad femenina ha sido ignorada de manera ostentosa tanto en la cultura en general como en los estudios académicos sobre la masculinidad, lo que de alguna manera se refleja en unas estructuras sociales complejas que justamente relacionan la masculinidad inevitablemente con lo masculino y, por extensión, con el poder y el dominio. ¿Por qué? Quizá porque la masculinidad se ha relacionado tradicionalmente con el ejercicio del poder, la legitimidad y el privilegio, de la misma forma en que de manera simbólica hace referencia al poder del Estado y a la distribución desigual de la riqueza.

La masculinidad, siguiendo la argumentación de Halberstam, se ramifica hacia el patriarcado y la familia, representando por extensión el poder de la herencia. Lo que denominamos «masculinidad dominante» sería entonces una relación natural entre lo masculino y el poder, lo que irónicamente revierte en que podamos detectar y analizar la masculinidad precisamente cuando ésta abandona el cuerpo masculino burgués. Esta línea de argumentación devuelve a Halberstam al interés crítico del estudio de la masculinidad no normativa, como es el caso de la masculinidad femenina. Halberstam utiliza al personaje de $\mathrm{M}$ en James Bond para ejemplificar su argumentación y hace referencia particularmente a Goldeneye, precisamente para destacar que el personaje que escenifica mejor la masculinidad en las películas de James Bond es precisamente M, en parte porque de alguna manera,

9 WOOLF, Virginia, «Professions for Women» (1931).

http://s.spachman.tripod.com/Woolf/professions.htm. Fecha último acceso: 12 agosto 2010 [Traducción propia].

10 HALBESTAM, Judith, «An Introduction to Female Masculinity», en ADAMS, Rachel y SAVRAN, David (eds.), The Masculinity Studies Reader. Oxford, Blackwell, 2002, pp. 355-375.

11 HALBESTAM, Judith, Female Masculinity. Durham, Duke University Press, 1998.

12 En este sentido, cabe destacar que el traductor al español del libro de Halberstam destaca la dificultad de la tarea: masculinity, male, maleness, femininity, female, feminine, introducen matices que en la lengua española quedan reducidos a masculinidad y feminidad, perdiéndose la distinción entre sexo/género tan marcada en la lengua inglesa. 
sirve para destacar la farsa de la representación del propio Bond. Es M quién convence a la audiencia de que el sexismo y la misoginia no son únicamente partes y/o parcelas de la masculinidad normativa (esto es, vinculada al cuerpo masculino).

La adolescencia femenina es una etapa de crisis, ya que constituye un proceso de transformación de niña a mujer en una sociedad dominada por los hombres. De acuerdo a Halberstam, si para los chicos se trata de un rito de paso a una posición más elevada en cuanto a poder social se refiere, en el caso de las chicas se trata de una lección de contención, castigo y represión. El tomboyism (las niñas con comportamiento masculino: «machotas», por así decirlo), que se asocia al deseo de algunas niñas por las mayores posibilidades de libertad y movilidad de los niños, refleja también ciertas ansias de independencia y realización personal. En el momento de la adolescencia, los instintos hacia el tomboyism de las niñas intentan remodelarse hacia formas de feminidad adecuadas al modelo social concreto. En este sentido también, la masculinidad femenina se sitúa como un terreno de investigación fructífero, aunque solo sea porque es a menudo interpretada como una señal incluso patológica de falta de identificación, de desajuste, ya que apunta al deseo de ser y tener un poder que para las niñas estará siempre fuera de alcance.

Finalmente, para Halberstam, la conclusión es que la masculinidad es no solamente múltiple, sino que determina, condiciona y modula a todos los seres culturales, sean varones o hembras. Por ello, el estudio de las masculinidades más allá de la masculinidad normativa (hombre blanco burgués) es críticamente relevante y culturalmente subversivo, ya que cuestiona la posición central dominante de la masculinidad como estandarte de la estabilidad de género y referencia de las posibles desviaciones, al tiempo que permite diseccionar cómo se construye la masculinidad en el discurso.

El pensamiento de Judith Halberstam contiene, a mi modo de ver, ramificaciones críticas más allá de los estudios queer en que la crítica estadounidense ha sido encapsulada y que nos pueden aportar nuevas perspectivas y por ende nuevas lecturas, en este caso sobre la narrativa británica de mujeres en el siglo XIX. En una primera aproximación dentro del caso que nos ocupa, caben dos ejes alrededor de los cuales se puede pivotar tomando como punto de partida el planteamiento sobre la masculinidad femenina de esta crítica norteamericana. Por una parte, la consideración de las mujeres escritoras en sí misma, como artistas y creadoras en una sociedad eminentemente patriarcal que concibe a la mujer como complemento al hombre, ocupando la esfera de lo privado, mientras la esfera pública se concibe como exclusivamente masculina. Por otra parte, la consideración de los textos propiamente dichos y de las posibilidades y terrenos que se exploran en ellos. Virginia Woolf, referente ineludible en lo que se refiere a la mujer novelista británica y a los estudios de género en el entorno anglosajón, ya afirma que la mujer escritora tiene ante sí un reto: matar al ángel de la casa si realmente quiere crear, si quiere escribir. También afirma que la misma existencia de la mujer escritora hace tambalear al patriarcado, en tanto en cuanto apunta a la posibilidad de que la 
mujer pueda tener una mente propia, un pensamiento independiente, lo que en la sociedad británica del siglo XIX se considera generalmente un atributo inherentemente masculino.

\section{MUJERES NOVELISTAS Y NOVELAS DE MUJERES}

[...] una mujer debe tener dinero y una habitación propia para poder escribir novelas; y esto, como veis, deja sin resolver el gran problema de la verdadera naturaleza de la mujer y la verdadera naturaleza de la novela ${ }^{13}$

Como hemos visto, la sociedad británica del siglo XIX es, en sentido amplio, una sociedad burguesa, puritana y eminentemente patriarcal. La mujer está recluida en el espacio doméstico y se convierte en estandarte de los valores morales que cabe transmitir de generación en generación. En términos generales, y con grandes diferencias entre el panorama que se respira a principios del siglo XIX (en la era de Jane Austen, por así decirlo) y a principios del siglo XX (en la era de Virginia Woolf), la mujer es considerada un ser frágil, etéreo, vulnerable, inferior al hombre; su función principal es, por supuesto, la procreación y transmisión de la cultura y, por tanto, debe ser protegida y preservada del mundo para garantizar que pueda llevar a cabo su misión en el engranaje social. Todo lo que atenta contra este modelo se considera subversivo y peligroso y debe ser reprimido, escondido o silenciado.

En este panorama, la novela florece y se establece como género literario dominante. La mujer de clase media, a menudo ociosa, se lanza a leer novelas y resulta, finalmente, que el público lector del momento es eminentemente femenino. En una época en que todavía no hay radio ni, por supuesto, televisión, la lectura de novelas se convierte en una de las principales formas de entretenimiento. La novela es el género que domina el panorama literario del siglo XIX en Inglaterra, especialmente durante la era victoriana, cuando se impone la publicación serializada (con la notoria excepción de las hermanas Brontë), que también incide en la enorme difusión y popularidad del género en este momento. Pero, por si fuera poco, y de manera aún más irónica si cabe, la mujer se lanza a la escritura con tal fervor que la proliferación de mujeres novelistas durante este periodo es cuando menos chocante, si tenemos en cuenta que el concepto de mujer novelista es un ejemplo de lo que Judith Halberstam articula como mujer masculina (the female masculine), de acuerdo a la ideología dominante. Cabe decir, antes de seguir adelante, que la Reina Victoria en sí misma es una afronta contra este discurso, por ser un buen ejemplo de mujer masculina. De Jane Austen a Virginia Woolf, la mujer se lanza a la novela y pretende profesionalizarse como escritora, de la misma manera que

${ }^{13}$ WOOLF, Virginia, Una habitación propia. Traducción de Laura Pujol. Seix Barral, 2009 [1929], p. 10. 
ocurre con los novelistas en general y a lo largo de todo el siglo. La mujer novelista no escribe solamente para entretenerse, sino que a menudo lo hace como profesión para ganarse la vida y, siendo una profesión ciertamente arriesgada para una mujer, al ser considerada una ostentación indecorosa, al menos de independencia e intelecto, lo hace a veces disfrazada de hombre, bajo un pseudónimo masculino.

La producción novelística femenina durante todo este largo siglo XIX es un buen exponente de los argumentos presentados hasta el momento. Así, entre las mujeres novelistas de este largo período, y más allá de las novelistas de la época reconocidas como canónicas (Jane Austen, las hermanas Brontë, Elizabeth Gaskell, George Eliot y Virginia Woolf principalmente), se puede mencionar a Fanny Burney, Elizabeth Inchbald, Mary Wollstonecraft, Anne Radcliffe, Mary Russell Mitford, Mary Shelley, Dinah Craig, Caroline Norton, Ellen Wood, Mary Elizabeth Braddon, Eliza Linton, Florence Marryat, Charlotte Yonge, Olive Schreiner, V. F. Martin, Margaret Oliphant, George Egerton, Sarah Grand, Mona Caird y May Sinclair, por citar algunas. Su estatus como escritoras profesionales representa un cuestionamiento de los planteamientos patriarcales del momento y apunta a su masculinidad (irónicamente muchas de ellas adoptaron pseudónimos masculinos, como se ha dicho), puesto que son mujeres con una profesión en una sociedad que relega a la mujer a la esfera doméstica únicamente. La mujer encuentra en este género todavía joven en las letras inglesas una forma de expresión adecuada para explorar su propio universo. Entre ellas, y por motivos de espacio, destacaré algunos casos con el fin de probar la argumentación establecida hasta el momento.

Virginia Woolf argumenta en su obra Un cuarto propio ( $A$ Room of One's Own) que para poder escribir la mujer necesitaba, en primera instancia, un cuarto propio. Woolf se centra en Jane Austen, Charlotte y Emily Brontë y George Eliot para defender su argumentación según la cual, para ser novelista, la mujer del siglo XIX tiene que «renunciar a su maternidad», pues las dos cosas eran incompatibles. Al carecer de cuarto propio, argumenta, la mujer tiene que escribir sus obras en el salón de estar de la casa, en compañía. Woolf habla de la mujer como entrenada, de forma natural, en la observación de las personas. Por todo ello, según ella, se lanza a escribir novelas y no poesía, por ejemplo. La conclusión a la que llega Woolf es que la mujer comienza a escribir abiertamente en el siglo XIX y que, cuando lo hace, elige la novela por ser el género más accesible a ella en forma y contenido. Es cierto que un repaso a la novelística de mujeres del siglo XIX en Inglaterra en el sentido más amplio nos dará como respuesta que Woolf se equivoca. Muchas mujeres escritoras no solamente fueron casadas, sino que fueron madres. Sin embargo, Woolf no se equivoca en valorar las enormes dificultades con que se tropieza la mujer cuando quiere aspirar a ser novelista, a desarrollar una mente propia, una auténtica aberración en el entorno histórico-cultural al que nos estamos refiriendo. 
Mary Wollstonecraft (1759-1797) se vio forzada por las circunstancias familiares a ganarse la vida desde muy temprano como señorita de compañía, institutriz, modista y maestra, empezando a escribir también desde muy temprano, motivada por sus inquietudes por el cambio social. Activista social y política, tuvo una relación tormentosa con un pintor francés antes de su relación con el filósofo William Godwin, con quien tuvo una hija, la también novelista Mary Shelley. Jane Austen (1775-1817), como otras escritoras novelistas del largo siglo XIX, permaneció soltera y dependiente económicamente de su padre primero y de uno de sus hermanos a la muerte del primero, desafiando el sistema y optando por la posición marginal respecto de la sociedad, la de «solterona». Mary Shelley (1797-1851) inició una relación con Percy Shelley, quien estaba casado, que le valió el ostracismo social y familiar. Aunque posteriormente se casó con el poeta, su prematura muerte forzó a Mary a volver a Inglaterra con su único hijo superviviente para dedicarse a la escritura como autora profesional con el fin de sobrevivir económicamente. Caroline Norton (1808-1877) se casó con George Norton para paliar la situación financiera de su madre, pero su matrimonio fue un completo desastre. Norton maltrató físicamente a Caroline durante años hasta que ella tomó la decisión de abandonarle. No solamente perdió la custodia de sus hijos, sino que se le negó el acceso a los mismos. Caroline entonces se convirtió en luchadora activa y férrea por defender los derechos de las mujeres casadas sobre sus hijos. Su lucha se centró en la batalla contra el Custody of Children Act de 1839. El Parlamento británico, en parte gracias a la labor de esta mujer, aprueba el Marriage and Divorce Act en 1857. George Eliot (Mary Anne Evans, 1819-1880), como es bien sabido, vivió una vida muy poco convencional desde que se trasladó a Londres para trabajar como editor asistente de la Westminster Review en 1851. De hecho, se convirtió en una figura escandalosa de desarrollo y autonomía profesional. Además, conoció a George Henry Lewes en 1851, quién estaba casado, e inició una relación con él. Se instalaron a vivir juntos y a partir de ese momento son marginados completamente por la sociedad de la época. Sarah Grand (1854-1943), por su parte, abandonó a su marido (un cirujano viudo del que tenía un hijo y con quien había viajado mucho) cambiando su nombre en ese momento por el de 'Madame' Sarah Grand. A partir de ese momento, se convierte en una figura líder dentro del movimiento feminista de la segunda mitad del siglo XIX, explorando la posibilidad de emancipación de las mujeres a nivel profesional. Como muchas mujeres de la época, su posicionamiento es ambiguo e incluso contradictorio en los temas referentes a la mujer, careciendo de la rebeldía que se puede detectar en otras escritoras. Finalmente en este apartado, George Egerton (1859-1945) se fuga con un hombre llamado Higginson, quién murió dos años más tarde, y durante este período conoce a Ibsen y a Nietzsche. Posteriormente, se casa con Egerton Clairmonte en 1893 para divorciarse en 1901 y volverse a casar con un agente teatral. Con ella nos enfrentamos a una mujer abiertamente intelectual, luchadora activa en la causa por la emancipación de las mujeres. La primera mención de Nietzsche en la literatura inglesa podemos encontrarla en su obra Keynotes, una colección de narraciones breves publicada en 1893. 
Estas novelistas son una muestra de mujeres masculinas, en tanto en cuanto su propia existencia es un desafío a la construcción que de la masculinidad/feminidad hace el patriarcado durante la era victoriana. Son igualmente una demostración de que la masculinidad trasciende el cuerpo masculino y es una construcción cultural. Nos ofrecen la posibilidad de explorar hasta qué punto la sociedad victoriana del siglo XIX se resiste a dinamitar la paridad del binomio género-sexo restringiendo la masculinidad al cuerpo masculino y por lo tanto, preservándola de contaminaciones con el fin de mantener la hegemonía de la masculinidad-hombre en el vértice superior de la escala de jerarquía social, política y cultural. Esto no es sorprendente en una era (y particularmente la segunda mitad de la década) caracterizada por las progresivas, constantes y crecientes demandas de las feministas ${ }^{14}$ por los derechos de la mujer a la educación, la representación política y la emancipación económica. Los movimientos sufragistas de la segunda mitad del siglo XIX tratan precisamente de eso, de dinamitar el patriarcado victoriano, a menudo atacando el binomio masculinidad-varón/feminidad-mujer. El resultado es que en muchos casos, las escritoras de esta época (como es el caso de Sarah Grand, por ejemplo) reflejan discursos contradictorios en sí mismos. En cuanto a las novelas escritas por mujeres durante este período, es relevante considerar la línea de argumentación que sigue Marina Warner conforme los textos (en este caso la novela) dan vida a lo imposible en el proceso de intercambio entre la fantasía del lector y la del escritor ${ }^{15}$. Para Warner, las historias que se narran se convierten siempre en formas muy poderosas de exploración de mundos alternativos. Y eso es lo que hace que la novela sea un espacio donde se pueda explorar el deseo, o en palabras de Catherine Belsey, que una historia sea siempre una cuestión de deseo:

«Las historias son sobre el deseo... el deseo transforma nuestras propias vidas en narrativas llenas de incertidumbre, suspenso y retos... nos convierte a todos en protagonistas, heroicos o legendarios, convierte a nuestros objetos de deseo en figuras de ficción» ${ }^{16}$.

Un punto crucial para la argumentación que propone este trabajo se sitúa alrededor de la novela como espacio donde el sujeto puede explorar cuestiones relacionadas con el deseo y el significado, teniendo la oportunidad de convertirse por un momento en dueño y señor de una historia. En relación a la masculinidad femenina tal y como la argumenta Halberstam, la novela se convierte en un espacio donde es posible explorar la otredad de la masculinidad femenina, las formas de masculinidad no normativa. El ansia de multiplicidad, de metamorfosearse, es además un deseo que, como toda forma de deseo, nunca culmina, sino que existe en cuanto permanece diferida. Las historias que contiene la novela son seduc-

14 Las sufragistas, en Inglaterra tanto las Sufragists como las Sufragettes.

15 WARNER, Marina, Fantastic Metamorphoses, Other Worlds. Oxford, OUP, 2002.

16 BELSEY, Catherine, Desire. Love Stories in Western Culture. Oxford, Blackwell, 1994, p. 208 [Traducción propia]. 
toras para el/la lector/a porque le permiten explorar su propia alteridad, su propia multiplicidad de una manera ciertamente segura. Por un momento se puede explorar la otredad, se puede articular el deseo a través de la transformación y metamorfosis. Y este momento efímero puede repetirse infinitamente, porque las historias son infinitas e interminables. Están siempre ahí.

Mary, A Fiction (Mary Wollstonecraft, 1788), Pride and Prejudice (Jane Austen, 1813), Wuthering Heights (Emily Brontë, 1847), Jane Eyre (Charlotte Bronté, 1847), Olive (Dinah Craik, 1850), East Lynne (Mrs Henry Wood, 1861), Lady Audley's Secret (Mary E. Braddon, 1862), Kirsteen (Margaret Oliphant, 1890), The Heavenly Twins (Sarah Grand, 1893), Daughters of Danaus (Mona Caird, 1894), Mary Olivier, A Life (May Sinclair, 1919); todas estas novelas ofrecen al público lector de la época la posibilidad de explorar espacios femeninos alternativos, la posibilidad de explorar la otredad, la masculinidad femenina. Curiosamente, la graduación de estas novelas en el tiempo, permite apreciar la evolución en las propias fantasías que la mujer escritora crea en sus novelas.

Mary, A Fiction es una novela de la activista social Mary Wollstonecraft. Se trata de un texto escrito con la intención de denunciar una serie de situaciones sociales que la autora encuentra discriminatorias para las mujeres a través de su personaje principal, Mary. El personaje de Mary es en la novela un ser socialmente independiente y descrito como una mujer masculina, siguiendo la argumentación de Halberstam, ya que se caracteriza por tener una mente curiosa, interesada por la filosofía más que por las novelas, por ejemplo. La novela narra como Mary es dejada de lado por su madre, criándose en una soledad que, lejos de enseñarle a ser mujer en la sociedad del momento, le otorga una libertad que le permite una comunión con la naturaleza acorde con el desarrollo de su propia naturaleza como ser humano, fuera de los límites impuestos por el código social vigente. Pero Mary es forzada a casarse más adelante por motivos económicos y por orden de su padre, y la novela se centra en explorar su reacción a este matrimonio y su deseo sobre todo de liberarse de lo que ella percibe como una responsabilidad e imposición social. Este tema del código social como opresivo y castrante para la mujer es explorado con detenimiento en la única novela de Emily Brontë, Wuthering Heights. El personaje principal de este texto, Cathy, vive una infancia sin madre en libertad, comunión con la naturaleza y fuera de los códigos sociales imperantes en el momento. Esta existencia «fuera de la ley», por así decirlo, hace posible la relación entre Cathy y Heathcliff, el huérfano adoptado por el Sr. Earnshaw, el padre de Cathy, un auténtico marginado social que carece de identidad y por lo tanto, está completamente fuera del sistema. El problema ocurre cuando Cathy pasa unos días en casa de los Sres. Linton, marcando simbólicamente su pasaje de la infancia a la madurez, su adolescencia. En ese momento, Cathy aprende lo que significa ser mujer en la Inglaterra victoriana y acaba volviendo a casa convertida en una señorita. El problema para Cathy es que no puede integrar este proceso de manera natural y vive el tránsito a la madurez como una auténtica castración y, en 
última instancia, aniquilación de su ser. En este sentido, Cathy ejemplifica muy bien la argumentación de Halberstam cuando habla de lo que la adolescencia supone para la mujer, a la vez que el texto atestigua hasta qué punto el código de comportamiento imperante podía resultar problemático para la mujer de la época. Emily Brontë no parece ver la reconciliación posible y Cathy muere dando a luz a una hija. Semejante figura femenina no puede ser integrada en la sociedad, que se encarga de eliminar la divergencia de manera cruel e implacable.

A primera vista, puede parecer curioso que se intente integrar a la aparentemente conservadora Jane Austen en este relato de historias alternativas, de divergencia. La obra central de esta autora, juntamente con Virginia Woolf la novelista más relevante de la historia de la novela inglesa, es Pride and Prejudice. En esta novela, Austen nos presenta a Elizabeth Bennet y nos cuenta una historia de mujeres, matrimonio y dinero, los temas centrales de su obra. A pesar de escribir sus novelas durante la primera década del siglo XIX, Austen es una autora de corte más neoclásico que romántico, donde la razón predomina, ordena y se concibe como esencial al mundo e inherente al ser humano, esto es, al hombre blanco. Elizabeth Bennet es, sin duda, una heroína excepcional y, dentro del universo austiniano, claramente subversiva. Las características que hacen de Elizabeth una heroína única tienen que ver con su mente, ya que Austen reivindica a través de ella la razón como inherente no solamente al hombre sino igualmente a la mujer. Elizabeth Bennet es, ante todo, una mujer inteligente, con raciocinio, capacidad de análisis, ironía e independencia de criterio. En un mundo en que las mujeres se casaban por necesidad, Elizabeth toma sus propias decisiones y elecciones. Las mujeres como Elizabeth generalmente se quedaban solteras (como la propia Jane Austen, seguramente), pero Austen premia a Elizabeth precisamente por su razón, su independencia de criterio y su capacidad de elegir. Haciéndola racional, Austen justamente eleva a Elizabeth y la hace «masculina», dado que la racionalidad se considera generalmente en esta época una cualidad inherente al hombre blanco. La novela de Austen busca la reconciliación, y por eso el sistema integra a Elizabeth, quien tiene como premio final al neoclásico Sr. Darcy.

Olive ha sido repetidamente relacionada con Jane Eyre, a la que sucede un par de años más tarde. Ciertamente existen muchos puntos de conexión entre los dos textos, ambos imbuidos de ideología puritana en el más puro sentido del concepto (ambos subrayan la importancia del trabajo y el sacrificio personal, la austeridad absoluta y un código ético-moral rígido y exhaustivo). Sin embargo, en ambos el personaje central es una mujer y una mujer emprendedora, en control de su propia vida, con iniciativa y decisión sobre su vida y con una mente clara, ágil y capaz. Podemos hablar tanto de Jane Eyre como de Olive como mujeres masculinas, en el sentido de que quieren ser independientes, autónomas y libres para tomar sus propias decisiones. De hecho, la crítica se refiere a Jane Eyre, narrada en primera persona, como la primera Bildungsroman femenina, y en este sentido, se eleva a Jane a la categoría de los personajes masculinos clásicos de la Bildungsroman. Olive, como sucesora de Jane Eyre, también se alimenta de estos elementos, e in- 
cluso se insiste en ambos casos en el físico poco agraciado de las protagonistas, una estrategia más para centrarnos en las carencias de su feminidad y resaltar lo que se presentan como virtudes, siendo éstas atributos tradicionalmente asociados a la masculinidad. Como $\mathrm{M}$ en James Bond, y a pesar de que la referencia pueda resultar chocante, Jane Eyre y Olive resultan adecuadas para estudiar la construcción de género en la sociedad victoriana. En ambos casos, los textos negocian la masculinidad de estas mujeres con su feminidad, para buscar un equilibrio final que permita su inserción en el patriarcado. Son textos tentativos, por cuanto exploran nuevas posibilidades, si bien en última instancia negocian con el patriarcado para buscar una solución de compromiso, reinserción y pacto social.

Los años 60 vieron la publicación de lo que dio en llamarse «novela sensacionalista" en Inglaterra. Sin duda, los dos mejores ejemplos en cuanto a la novela escrita por mujeres en este campo son East Lynne y Lady Audley's Secret. Ambas novelas son best-sellers de la época y abren temas de debate de primera línea en tono sensacionalista y con una elevada intensidad de trama. East Lynne se convirtió en su momento en un gran éxito comercial, con una tirada que la sitúa como una de las novelas más vendidas del siglo, un auténtico best-seller. Lady Audley's Secret es una novela de intriga, heredera de la tradición instaurada por la novela de Wilkie Collins, The Woman in White, serializada en 1859-1860. East Lynne cuenta la historia de Lady Isabel Vane y de su matrimonio con el Sr. Carlyle. Es una historia trágica de adulterio, divorcio y derechos sobre los hijos. Lady Audley's Secret, por su parte, es una historia criminal de abandono, bigamia y locura. En ambos casos, el espacio doméstico se presenta como terreno de ansiedad e inestabilidad. Lady Isabel y Lady Audley tienen poco en común, ya que una es víctima de su feminidad (como discurso cultural) mientras la otra, una mujer masculina, exprime y explota conscientemente su construcción cultural como mujer en el discurso político de la época en su propio beneficio. Tanto Lady Isabel como Lady Audley son distorsiones, espacios límites donde explorar cuestiones relevantes relacionadas con el papel de la mujer en el matrimonio, el divorcio, o la relación entre feminidad y maternidad. Los textos, contrariamente a lo que ocurre en Olive, no buscan la reconciliación sino que en última instancia castigan la desviación. Ambas mujeres se convierten en proscritas, deformadas física y mentalmente, castigadas por atentar contra el orden establecido por el patriarcado.

Las últimas décadas del siglo ven la publicación de textos que dejan el tono sensacionalista que hemos visto en los ejemplos citados y se comprometen más directamente en explorar alternativas más radicales al modelo dominante de feminidad de la sociedad victoriana. En Kirsteen, Margaret Oliphant nos presenta a una mujer emprendedora, rebelde, luchadora por su libertad e independencia, que desafía la estructura cerrada de clanes en Escocia para huir y establecerse profesionalmente en Londres. Kirsteen es una mujer masculina, siguiendo la argumentación de Judith Halberstam. Su independencia de mente, su determinación y su iniciativa a luchar por su vida, juntamente con su progreso y evolución en el mundo de los negocios son emblemáticos del self-made man, en el sentido más 
puro del concepto. La ambición de Kirsteen es una ambición masculina porque es una ambición de desarrollo personal. Si leemos la novela como espacio alternativo de exploración del deseo, podemos leer el texto como un espacio donde la lectora de la época que vive una vida enclaustrada y preservada del mundo, puede vivir la fantasía de la masculinidad, de las posibilidades que la masculinidad ofrece y que la feminidad niega en la cultura de la época. En esta línea pero de manera diferente, tanto The Heavenly Twins como Daughters of Danau presentan curiosamente personajes muy radicales de pensamiento, con ideas claramente subversivas, si bien se mueven siempre dentro de los cánones aceptables del matrimonio. En ambos casos, el debate alrededor de lo que dio en llamarse the new woman, es críticamente fructífero y socialmente relevante. Esta new woman o «mujer nueva» tiene mucho que ver con una feminidad más masculina, una feminidad que se apropia progresivamente de elementos propios de la masculinidad para tratar de integrarlos y conseguir eso: una nueva mujer. Algunas de las novelas escritas por mujeres a finales de siglo se convierten en territorios donde explorar las posibles ramificaciones que una feminidad masculina, este nuevo género híbrido, tiene en un contexto social y cultural tan determinado como el final de la era victoriana y el principio de la era eduardiana, con la promesa de cambio y apertura que inevitablemente trae consigo.

Finalmente, en Mary Olivier, A Life, anticipamos la obra de Virginia Woolf y la novela modernista, con la exploración a través del monólogo interior del subconsciente femenino. De nuevo creo que es interesante considerar críticamente la exploración que del subconsciente femenino lleva a cabo esta novela, que se inspira en el psicoanálisis y que - como hará luego Virginia Woolf- reivindica el subconsciente como terreno común e híbrido, ni masculino ni femenino, dinamitando con ello el binomio masculino-varón, femenino-hembra. Mary es, además, un personaje poco convencional en cuanto a construcción de género se refiere. La novela explora el terreno de una feminidad masculinizada desde el momento en que la aspiración de la protagonista se centra alrededor de su desarrollo como individuo y propone un modelo de feminidad alternativo y más masculino, siguiendo la argumentación de Halberstam.

\section{CONCLUSIÓN: HISTORIA(S) DE LA DIFERENCIA}

[...] un ser muy extraño, mixto. En el terreno de la imaginación, tiene la mayor importancia; en la práctica, es totalmente insignificante. Reina en la poesía de punta a punta de libro; en la Historia casi no aparece ${ }^{17}$

17 WOOLF, Virginia, Una habitación propia. Traducción de Laura Pujol. Seix Barral, 2009 [1929], p. 62. 
Así las cosas, la mujer novelista representa una afronta al código moral y de comportamiento dominante vigente a lo largo del siglo XIX en Inglaterra. Su mera existencia es una evidencia histórica de la individualidad y capacidad personal de un colectivo marginado por el estatus dominante y relegado a los márgenes de la historia. Como documento de valor histórico, las novelas que estas mujeres construyen vierten sobre el patriarcado perspectivas desde los márgenes del sistema que subvierten y cuestionan una ideología dominante que intenta presentarse a sí misma como única y coherente.

Más allá aún, la novela victoriana escrita por mujeres explora la posibilidad de una feminidad alternativa que invade el terreno de la masculinidad y se perfila como un género más híbrido, explorando la posibilidad de un modelo de mujer masculina según los cánones vigentes. La mujer masculina es un sueño, pero un sueño lleno de riesgos y contradicciones. En un siglo que plantea en sus inicios el debate en torno a la mujer con la publicación de Vindicación de los derechos de la mujer, la novela de mujeres se convierte en un terreno fructífero para explorar las posibilidades/alternativas al modelo de feminidad impuesto por el código ético-moral dominante de la era victoriana.

Del mismo modo, la existencia de un público lector eminentemente femenino constata también la curiosidad de la mujer de la época por explorar su propia multiplicidad, su otredad. La mujer, que vive encerrada en el entorno doméstico, se sirve de la novela para escapar del mismo, aunque sea de forma virtual. Sin embargo, esa posibilidad de metamorfosearse de forma vicaria juega, sin duda, un papel relevante también como fuente de inspiración para el cambio social real.

Finalmente, la importancia de este tipo de fuentes distintas a las usadas tradicionalmente por los historiadores para conocer historia(s) alternativa(s), la(s) historia(s) de la diferencia es, a mi modo de ver, incuestionable si se pretende tener una visión amplia y compleja de una realidad social en un momento histórico determinado. En una sociedad como la de Inglaterra en el siglo XIX, que carece de educación universal o de derechos civiles comunes a todos los ciudadanos, poder acceder a fuentes que ofrezcan una mirada a/desde los grupos desfavorecidos, supone poder acceder a sus historias. Posiblemente, el conocimiento de las historias de la diferencia pueda alterar la noción de la Historia, incluso cuestionar su existencia como única, sólida e incuestionable. 